\title{
Extract from Ribes nigrum leaves in vitro activates nitric oxide synthase (eNOS) and increases CD39 expression in human endothelial cells
}

\author{
Boguslawa Luzak • Magdalena Boncler • Joanna Rywaniak • Dominika Dudzinska • \\ Marek Rozalski • Urszula Krajewska • Ewa Balcerczak • Anna Podsedek • \\ Malgorzata Redzynia • Cezary Watala
}

Received: 3 December 2013 / Accepted: 10 November 2014 / Published online: 19 November 2014

(C) University of Navarra 2014

\begin{abstract}
The aim of the present study was to evaluate whether blackcurrant leaf extract (BLE) modulates endothelium antithrombotic function, namely increases the expression/activity of ADPase (CD39) and augments the production of nitric oxide in human umbilical vein endothelial cells (HUVEC). It was found that BLE with proanthocyanidins $(60 \%$ of the total polyphenol content) increased the CD39-positive endothelial cell fraction (up to $10 \%$ for $2.5 \mu \mathrm{g} / \mathrm{ml}$, and up to $33 \%$ for $15 \mu \mathrm{g} / \mathrm{ml}, p<0.05$ or less) in a concentration-dependent manner, and enhanced endothelial nitric oxide synthase (eNOS) activation (T495 phosphorylation decreased by $31 \pm 6 \%$ for $2.5 \mu \mathrm{g} / \mathrm{ml}$ and $48 \pm 6 \%$ for $15 \mu \mathrm{g} / \mathrm{ml}$; S 1177 phosphorylation increased by $13 \pm 3 \%$ for $2.5 \mu \mathrm{g} / \mathrm{ml}$ and $18 \pm 7 \%$ for $15 \mu \mathrm{g} / \mathrm{ml}$, compared to untreated cells, $p<0.05$ or less). Additionally, incubation for 24 or $48 \mathrm{~h}$ with BLE at a lower range of polyphenol
\end{abstract}

B. Luzak $(\bowtie) \cdot$ M. Boncler $\cdot$ J. Rywaniak $\cdot$ D. Dudzinska

C. Watala

Department of Haemostasis and Haemostatic Disorders,

Medical University of Lodz,

6/8 Mazowiecka Street, 92-215 Lodz, Poland

e-mail: boguslawa.luzak@umed.lodz.pl

M. Rozalski · U. Krajewska • E. Balcerczak

Department of Pharmaceutical Biochemistry, Molecular

Biology Laboratory, Medical University of Lodz,

Lodz, Poland

A. Podsedek $\cdot$ M. Redzynia

Department of Biotechnology and Food Sciences, Institute of

Technical Biochemistry, Lodz University of Technology,

Lodz, Poland concentrations, significantly increased cell viability with a maximal effect at $2.5 \mu \mathrm{g} / \mathrm{ml}$ (viability increased by $24.8 \pm 1.0 \%$ for $24 \mathrm{~h}$ and by $32.5 \pm 2.7 \%$ for 48 -h time incubation, $p<0.0001)$. The increased CD39 expression and the increased eNOS activation in HUVEC can be regarded as the beneficial markers of the improvement of antiplatelet action of endothelial cells. Unexpectedly, these assumptions were not confirmed in the experimental model of platelet-endothelial cell interactions. These observations lead to the conclusion that BLE may improve endothelial cell viability at low physiological concentrations without affecting the antiplatelet action of endothelium.

Keywords Blackcurrant leaf extract - eNOS activation . CD39 - ecto-ADPase $\cdot$ Endothelial cells $\cdot$ Cardiovascular disease

\section{Introduction}

The endothelium mediates a number of responses (relaxation or contraction) of arteries and veins from animals and humans, but the special role of endothelial cells is the regulation of blood platelet functions. Platelets, in general, appear to be designed to adhere to the vessel wall only when endothelial integrity is disrupted and several mechanisms, such as the secretion of nitric oxide (NO) and prostacyclin, evolved to prevent their adhesion to the intact endothelium. Both mediators are potent inhibitors of platelet adhesion and activation. The 
endothelial cells also produce an ecto-ADPase (CD39), which degrades ADP released from erythrocytes and aggregating platelets. The function of endothelial cells is dependent on many variables including lipid levels, blood pressure and also the normal ageing process, which influence the turnover and regeneration of endothelial cells, which may, in turn, result in abnormal function: the loss of ability to release a relaxing factor [8]. Under conditions of disrupted homeostasis such as those found in inflammatory states, platelets can even bind to the intact endothelium. This is partly because endothelium-dependent mechanisms of platelet inhibition are impaired, and partly because new adhesion molecules are expressed on the surface of activated endothelial cells. Several agents have been proposed as potential modulators of endothelial function. Most of the available approaches include pharmaceutical agents (statins, angiotensin converting enzyme inhibitors), dietary supplements (f.i. folic acid), functional foods and nutraceuticals [21]. Numerous epidemiological studies have indicated that diets rich in fruits, vegetables and beverages, such as red wine and tea, are associated with the reduced risk of cardiovascular diseases. Polyphenols may protect the cardiovascular system by preventing oxidation of low-density lipoprotein, platelet aggregation and adhesion and smooth muscle cell migration and viability. Alternatively, vascular protection may also be due to the direct action of polyphenols on the endothelial function [24].

Blackcurrant leaves (Ribes nigrum L.) are used in European traditional medicine for treating disorders of inflammatory nature, as for instance, rheumatic disease [27]. Several studies have focused on the therapeutic potential of blackcurrant with regard to hypertension and other cardiovascular-associated illnesses, neoplastic, neurodegenerative and ocular diseases and diabetic neuropathy [7]. It has been shown that blackcurrant seed oil acts as a platelet inhibitor and potentiates an anticoagulant effect by inhibiting fibrin formation [25]. Other reports have demonstrated the influence of blackcurrants on serum lipid profile: increased HDLcholesterol level and decreased triglyceride or total cholesterol [33], as well as reduced serum inflammatory markers [30].

The aim of the present study was to investigate the antithrombotic function of human umbilical vein endothelial cells (HUVEC) in the presence of blackcurrant leaf extract. The first section elaborates on of the procedure for obtaining a leaf extract rich in proanthocyanidins, the second provides an estimate of endothelial cell viability after incubation with an extract and selects the optimal concentration of extract for further analyses. The final section details the monitoring of selected parameters of endothelial cell function which might be related to the modulation of blood platelet reactivity. We hypothesise that the blackcurrant leaf extract may improve the antiplatelet action of endothelium by increasing CD39 expression and nitric oxide production, monitored as endothelial nitric oxide synthase (eNOS) activation and eNOS gene expression. The results demonstrated that blackcurrant extract rich in proanthocyanidins (up to $60 \%$ of the total content of polyphenols), used at a concentration of 2.5 to $15 \mu \mathrm{g} / \mathrm{ml}$, increased the CD39positive cell fraction and enhanced eNOS activation by increasing S1177 phosphorylation and decreasing T495 phosphorylation in the eNOS molecule. Unexpectedly, these assumptions were not confirmed in the experimental model of platelet-endothelial cell interactions, because we did not observe the significant changes in platelet reactivity after their incubation with the extract-treated HUVEC. In conclusion, our study provides evidence for a potential beneficial role of blackcurrant leaf extract in the regulation of endothelial function, but further studies are needed to resolve still existing ambiguities.

\section{Materials and methods}

Reagents

Chlorogenic acid; gallic acid; ellagic acid; myricetin; kaempferol; methyl gallate; quercetin; vanillin; (+)-catechin; 6-hydroxy-2,5,7,8-tetramethychroman-2-carboxylic acid (Trolox); 2,4,6-Tri(2-pyridyl)-s-triazine (TPTZ); 1,1-diphenyl-2-picrylhydrazyl (DPPH); 2,2 azinobis (3-ethylbenzothiazo-line-6-sulfonic acid) (ABTS); potassium persulphate, 5 -adenosine diphosphate (ADP); protease inhibitor cocktails; bovine deoxyribonuclease I (DNase I); BCA Kit, 3-(4,5-dimethylthiazol-2-yl)-2,5-diphenyltetrazolium bromide (MTT); enhanced avian HS RT-PCR kit; SYBR ${ }^{\circledR}$ Green JumpStart $^{\mathrm{TM}}$ Taq ReadyMix ${ }^{\mathrm{TM}}$; apyrase (EC 3.6.1.5) and adenosine 5'-triphosphate disodium salt (ATP) were purchased from Sigma-Aldrich (St. Louis, MO, USA). HPLC grade acetonitrile and acetic acid were purchased from J.T. Baker (Avantor Performance Materials, Inc. Center Valley, PA, USA). All other chemicals were reagent grade products purchased from $\mathrm{POCH}$ (Gliwice, 
Poland). Reagents for flow cytometry studies (BD ${ }^{\mathrm{TM}}$ Cytometric Bead Array (CBA) Cell Signalling Master Buffer Kit, BD ${ }^{\mathrm{TM}}$ Cytometric Bead Array (CBA) Phospho eNOS (T495) Flex Set, BD ${ }^{\mathrm{TM}}$ Cytometric Bead Array (CBA), Phospho eNOS (S1177) Flex Set, anti-human mAb CD61/PerCp, CD62/PE, PAC-1/ FITC, CellFix and Vacutainer ${ }^{\mathrm{TM}}$ containing 0.105-M buffered sodium citrate were from Becton Dickinson (San Diego, CA, USA). Anti-human mAb CD39/R$\mathrm{PE}$, mouse IgG1 (R-PE) isotype control were obtained from Ancell (Bayport, MN, USA). The Malachite Green Phosphate Assay Kit was from BioAssay Systems (Hayward, CA, USA).

\section{Characteristics of plant material}

Blackcurrant leaves (Ribes nigrum L.) were harvested in central Poland by hand on August 2009. The leaves were air-dried in a laboratory dryer at $40{ }^{\circ} \mathrm{C}$ for $8 \mathrm{~h}$, ground to a fine powder, and stored in closed vessels in the refrigerator.

Dried blackcurrant leaves were extracted three times with $70 \%(v / v)$ aqueous acetone while stirring at room temperature for 30,15 and $15 \mathrm{~min}$, followed by centrifugation (4000 rpm) for $15 \mathrm{~min}$. The solid to liquid ratio was 1:10 $(w / v)$ every time. After removal of acetone with a vacuum rotary evaporator (Rotavapor RII, Büchi, Switzerland) at $<40{ }^{\circ} \mathrm{C}$, the extract was submitted to a liquid-liquid partition using chloroform (six times, 1:1 v/ $v)$. The water fraction was concentrated in a vacuum, and lyophilized (Alpha 1-2 LD plus, Christ) giving a percentage yield of $20.6 \%$. For future analysis, $50 \mathrm{mg}$ of dry extract was dissolved in $10 \mathrm{ml} 10 \%(v / v)$ aqueous dimethyl sulfoxide (DMSO). The total content of polyphenols of the extract was determined using FolinCiocalteu reagent, according to the method described by Bordonaba at el. [3]. The gallic acid was used as a reference standard. The results are expressed as milligramme gallic acid equivalent (GAE) per gramme of dry weight of extract (mg GAE/g). Determination of total content of flavan-3-ols in the extracts was performed using the vanillin assay according to the Swain and Hillis protocol [26]. The flavanol content was calculated from a calibration curve, using $(+)$ catechin as a standard. The results are expressed as milligramme $(+)$ catechin equivalents per gramme of dry weight of extract (mg CE/g). The proanthocyanidins were determined after acid depolymerisation to the corresponding anthocyanidins as described by Rösch et al. [23]. The content of proanthocyanidins ( $\mathrm{mg}$ cyaniding equivalents/g of extract) was calculated by the molar extinction coefficient of cyanidin $(\varepsilon=$ $17,360 \mathrm{~L} \mathrm{~mol}^{-1} \mathrm{~cm}^{-1}$ and molar mass $287 \mathrm{~g} \mathrm{~mol}^{-1}$ ). The content of hydrolysable tannins in the obtained extracts was estimated by high-performance liquid chromatography (HPLC) after the acidic hydrolysis of gallotannins into methyl gallate and the acidic hydrolysis of ellagitannins into ellagic acid. The methyl gallate and ellagic acid were analysed directly by HPLC as described below, and quantified as milligrammes of methyl gallate or ellagic acid equivalents per gramme of extract, respectively [4]. Free flavonols were identified and quantified in the extract after acid hydrolysis of flavonol conjugates. An aliquot $(3.75 \mathrm{mg}$ ) of extract was dissolved in $0.75 \mathrm{ml}$ of water, and added to $0.25 \mathrm{ml}$ of $0.2 \mathrm{M}$ ethylenediaminetetraacetic acid (antioxidant), followed by $0.25 \mathrm{ml}$ of concentrated hydrochloric acid and $1.25 \mathrm{ml}$ of methanol. The mixture was refluxed at $85{ }^{\circ} \mathrm{C}$ for $0.5 \mathrm{~h}$. After cooling, the flavonol aglycones were analysed directly by HPLC at $360 \mathrm{~nm}$.

HPLC-PDA analysis of phenolic compounds was performed using an analytical reversed-phase HPLC system (Waters) with 2707 autosampler and 1525 binary HPLC pump coupled to a 996 photodiode array detector (2998), controlled by Waters Breeze 2 software (Waters, Milford, MA). Separation was performed on a SYMMETRY C18 (250 $\mathrm{mm} \times$ $4.6 \mathrm{~mm}, 5 \mu \mathrm{m}$ ) column (Waters). The binary mobile phase, according to Dyrby et al. [4], consisted of water and formic acid at a ratio of 90:10 $(\mathrm{v} / \mathrm{v})$, respectively (solvent $\mathrm{A}$ ), water, acetonitrile and formic acid in the ratio of 49:50:10 $(v / v / v)$, respectively (solvent B). The separation of phenolics were performed using the following gradient programme with a flow rate of $1 \mathrm{ml} / \mathrm{min}: 0 \mathrm{~min}, 88 \% \mathrm{~A}+$ $12 \% \mathrm{~B} ; 26 \mathrm{~min}, 70 \% \mathrm{~A}+30 \% \mathrm{~B} ; 40-43 \mathrm{~min}$, $0 \% \mathrm{~A}+100 \% \mathrm{~B} ; 43-50 \mathrm{~min}, 88 \% \mathrm{~A}+12 \% \mathrm{~B}$. The detector was set at $320 \mathrm{~nm}$ for hydroxycinnamic acid derivatives and $360 \mathrm{~nm}$ for flavonols, and these compounds were identified on the basis of absorption spectra (200-500 nm). The amount of hydroxycinnamic acids was expressed as chlorogenic acid equivalents and flavonols as quercetin equivalents. The flavonol aglycons were identified by comparing the retention times and UV spectra of the analytes with those of the reference compounds. 
Determination of radical scavenging activity $\left(\mathrm{ABTS}^{\bullet+}\right.$ assay), $\mathrm{DPPH}^{\bullet}$ scavenging activity and antioxidant reducing power (FRAP assay) of the extracts

The scavenging effects on stable $\mathrm{ABTS}^{\bullet+}$ radicals was determined according to the procedure described by Re et al. [22]. The ferric reducing antioxidant power (FRAP assay) was evaluated according to the procedure developed by Benzie and Strain [2]. DPPH (2,2-diphenyl-1-picrylhydrazyl) scavenging activity was determined using the method of Kim et al. [11]. The results for all three methods are expressed as micromoles of trolox equivalent per gramme of extract (trolox equivalent antioxidant capacity (TEAC)).

\section{Maintaining of HUVEC culture}

Human umbilical vein endothelial cells (HUVEC) and all reagents needed for cell culture were purchased from Cascade Biologics (Portland, OR, USA). The HUVEC were cultured according to the manufacturer's instructions and the cells underwent 2-6 passages.

Determination of the effect polyphenol extract from blackcurrant leaf on HUVEC viability

HUVEC were seeded onto 96-well plate $(10,000$ cells/well) and these cells were further grown in a humidified atmosphere of $5 \% \mathrm{CO}_{2}$ in air at $37{ }^{\circ} \mathrm{C}$ for $24 \mathrm{~h}$. Cells were then exposed to polyphenol extract (final concentrations $0.05,0.1,0.25,0.5,1$, $2.5,5,10,25,30,50$ and $100 \mu \mathrm{g} \mathrm{GAE} / \mathrm{ml}$ blackcurrant extract) for three different periods of time: 1, 24 and $48 \mathrm{~h}$. After incubation, the culture medium containing polyphenolic extract was replaced with fresh medium and cell viability was determined by the MTT assay [9]. The cells were treated with the MTT reagent for $2 \mathrm{~h}$. MTTformazan crystals were dissolved in $20 \%$ SDS and $50 \%$ DMF at pH 4.7 and absorbance was read at $570 \mathrm{~nm}$ on multifunctional ELISA-plate reader Victor $^{3}$ (PerkinElmer, Turku, Finland). The effect of the extract on HUVEC was analysed as the relative cell viability in comparison to the untreated cells, and expressed as a percent of control sample.
Analysis of CD39/NTPDase expression in blackcurrant extract-treated HUVEC

HUVEC were cultured at a density of $5 \times 10^{4}$ cells/well for $24 \mathrm{~h}$ in 6-well plate to confluence and then treated with the blackcurrant leaf extract ( 2.5 and $15 \mu \mathrm{g}$ GAE/ $\mathrm{ml}$ ). Following 24-h incubation, the culture medium containing polyphenolic extract was replaced with fresh medium and another $24 \mathrm{~h}$ later, the cells were detached from the plate $(0.01 \%$ EDTA, $0.1 \%$ bovine serum albumin (BSA)), centrifuged ( $6 \mathrm{~min}, 100 \times g$ ), resuspended in a staining solution (phosphate-buffered saline (PBS), $1 \%$ BSA, $0.01 \%$ sodium azide) and stained for $30 \mathrm{~min}$ with the monoclonal antibodies specific to human CD39 antigen. Mouse IgG1 (R-PE) isotype control was used as a negative control. After staining, the cells were washed twice, suspended in a staining buffer and analysed using an LSR II Flow Cytometer (Becton Dickinson, San Diego, CA, USA).

Analysis of the NTPDase activity

The apyrase (NTPDase) activity in the presence of blackcurrant leaf extract was determined by malachite green assay used to the measuring inorganic phosphate release from ATP according to manufacturer's protocol. The solution preparation, enzyme reactions and standard curve were performed in disposable sterile phosphatefree plastic labware. Apyrase activity was determined in phosphate-free $50 \mathrm{mM}$ Tris buffer, $\mathrm{pH} 7.5$ containing $1 \mathrm{mM} \mathrm{CaCl} 2$. Before the addition of a substrate of the enzymatic reaction (ATP at final concentration of $3 \mathrm{mM})$, apyrase $(0.1 \mathrm{U} / \mathrm{ml})$ was incubated with the extract in the concentrations: $0.25,0.5,1,2.5,10$ and $15 \mu \mathrm{g} \mathrm{GAE} / \mathrm{ml}$ for $15 \mathrm{~min}$ at $37^{\circ} \mathrm{C}$. The enzymatic reaction was provided by $15 \mathrm{~min}$ at $37^{\circ} \mathrm{C}$, and next it was stopped after by the dilution of the reaction mixtures with buffer (if it was necessary) and/or by the transfer of $80 \mu \mathrm{l}$ of reaction buffer to a 96-well plate and the subsequent addition of $20 \mu$ of Malachite Green Reagent. Calibration curve and Malachite Green Reagent were prepared according to Malachite Green Kit producer instruction. Absorbance was read at $655 \mathrm{~nm}$. Simultaneously, the interference of the absorbance for blackcurrant extract alone with the absorbance for the reaction Pi-malachite green product was estimated and it was excluded that extract might influence on the spectophotomeric measurements in this assay. 
Monitoring of 1177-Ser and 495-Thr phosphorylation in eNOS protein

HUVEC $\left(1 \times 10^{6}\right)$ were placed in a $75 \mathrm{~cm}^{2}$ culture bottles and after $24 \mathrm{~h}$, the cells were incubated with 2.5 or $15 \mu \mathrm{g} \mathrm{GAE} / \mathrm{ml}$ blackcurrant leaf extract for further $24 \mathrm{~h}$. After the incubation, the cells were harvested by trypsinization and centrifuged $(100 \times g, 6 \mathrm{~min}, \mathrm{RT})$. The obtained cell pellets were subsequently denatured with denaturation buffer previously diluted in deionised water and supplemented with protease inhibitor cocktail and phosphatase inhibitor cocktail $2\left(5 \mathrm{~min}, 100{ }^{\circ} \mathrm{C}\right)$. The presence of DNA in denaturated samples were remedied by adding DNase I $\left(15 \mathrm{~min}, 37^{\circ} \mathrm{C}\right)$ which was further inactivated by sample heating at $75^{\circ} \mathrm{C}$ for $10 \mathrm{~min}$. The obtained cells lysates were stored at $-70^{\circ} \mathrm{C}$ until determination of protein concentration by $\mathrm{BCA}$ assay or eNOS phosphorylation. Before further analysis, the samples were centrifuged to pellet the debris $(10,000 \times g, 3 \mathrm{~min})$. The measurements of endothelial nitric oxide synthase (eNOS) phosphorylation at Ser1177 and Thr-495 were performed with the use of the commercial BD ${ }^{\mathrm{TM}}$ Flex Set Kits, for Phospho eNOS S1177 and Phospho eNOS T495 according to the manufacturer's instructions. The samples were measured on a Becton Dickinson FACSCanto II flow cytometer and the results were analysed with Becton Dickinson FCAP Array software.

\section{Determination of eNOS gene expression}

To estimate the eNOS gene expression, HUVEC ( $1 \times$ $10^{6}$ ) were located in $75-\mathrm{cm}^{2}$ culture bottles (NUNC, Roskilde, Denmark) and further grown for $48 \mathrm{~h}$. The culture medium was then replaced with blackcurrant leaf extract containing medium for $24 \mathrm{~h}$ (the final concentrations of $0,0.25,2.5$ and $15 \mu \mathrm{g}$ of GAE/ $\mathrm{ml})$. The HUVEC were than rinsed four times with PBS, scraped and spun down $\left(250 \times g, 6 \mathrm{~min}, 4{ }^{\circ} \mathrm{C}\right)$. Finally, $1 \mathrm{ml}$ of fenozole was added to the cell pellet for RNA isolation. RNA was isolated by Total RNA Prep Plus Minicolumn Kit (A\&A Biotechnology, Poland). The isolated RNA had an $A_{260 / 280}$ ratio of 1.6-1.8. The reverse transcriptase (RT) reaction was performed using Enhanced Avian HS RT-PCR Kit, according to the two-step manufacturer's protocol. Reaction mixture for Reverse Transcription contained at the first step $0.01 \mu \mathrm{g} / \mu \mathrm{l}$ of total RNA, $1 \mu \mathrm{l}$ anchored oligo (dT)23 (the final concentration of $3.5 \mu \mathrm{M}), 1 \mu \mathrm{l}$ of deoxynucleotide (dNTP) mix (the final concentration of $500 \mu \mathrm{M}$ each dNTP) and deionised, nuclease-free water. The mixture was centrifuged and incubated at $70{ }^{\circ} \mathrm{C}$ for $10 \mathrm{~min}$. Then, the mixture was chilled on ice and the following components for the second step were added: $2 \mu \mathrm{l}$ of $\times 10$ buffer for AMV-RT, $1 \mu$ of RNase inhibitor, $1 \mathrm{U} / \mu \mathrm{l}$ and $1 \mu \mathrm{l}$ of enhanced avian RT $1 \mathrm{U} / \mu \mathrm{l}$. The mixture was then mixed, centrifuged and incubated at $42{ }^{\circ} \mathrm{C}$ for $50 \mathrm{~min}$. Total volume was $20 \mu \mathrm{l}$. The complementary DNA (cDNA) was used immediately or stored at $-20{ }^{\circ} \mathrm{C}$. Before the quantitative analysis of gene expression by real-time PCR reaction, the parameters were checked using qualitative PCR. The PCR reaction mixture for PCR amplification consisted of a cDNA template, $0.5 \mu \mathrm{M}$ of each primer, $\times 10$ AccuTaq Buffer, $0.5 \mathrm{U}$ of AccuTaq LA DNA Polymerase Mix, $0.2 \mathrm{mM}$ each dNTP, and water to a final volume of $20 \mu \mathrm{l}$. A negative control was included in each experiment (the sample without a cDNA template). The primer sequences for both genes, target eNOS and reference GAPDH (glyceraldehyde phosphate dehydrogenase), were designed by using Primer3 software: The WWW primer tool (http://biotools.umassmed.edu/bioapps/ primer3_www.cgi). Real-time PCR was performed on the corresponding cDNA synthesised from each sample using an MX3005PтM System. The eNOS gene and a reference $G A P D H$ were amplified in parallel for each sample in separate wells, during the same PCR run. GAPDH was utilised as an internal positive control and as a normaliser for the correction of gene expression. For each PCR run, a reaction mixture was prepared consisting of $12.5 \mu \mathrm{l}$ SYBR $^{\circledR}$ Green JumpStart ${ }^{\mathrm{TM}}$ Taq ReadyMix ${ }^{\mathrm{TM}}, 0$. $5 \mu \mathrm{l}$ forward primer (final concentration $0.2 \mu \mathrm{M}$ ), $0.5 \mu \mathrm{l}$ reverse primer, $9 \mu \mathrm{l}$ nuclease-free water, and $2.5 \mu \mathrm{l}$ template cDNA. The thermal cycling conditions comprised an initial denaturation step at $95{ }^{\circ} \mathrm{C}$ for $2 \mathrm{~min}, 35$ cycles at $94{ }^{\circ} \mathrm{C}$ for $30 \mathrm{~s}, 59^{\circ} \mathrm{C}$ for $30 \mathrm{~s}$ and $72{ }^{\circ} \mathrm{C}$ for $30 \mathrm{~s}$ and a final extension step at $72{ }^{\circ} \mathrm{C}$ for $3 \mathrm{~min}$. After reaction, a melting curve was performed to confirm reaction specificity. Experiments for all samples were performed in triplicate. The quantification of eNOS messenger RNA (mRNA) level was carried out by the ${ }^{\Delta \Delta}$ CT method, which was described previously by Livak and Schmittgen [16], using GAPDH as a reference housekeeping gene. 
Measurement of platelet reactivity in the presence of HUVEC

\section{Blood collection and platelet isolation}

Blood was collected from 12 healthy donors ( 3 men and 9 women, with a mean age of $26.1 \pm 4.4$ years) into a vacuum tube containing $0.105-\mathrm{M}$ buffered sodium citrate. None of the donors had taken aspirin or other drugs affecting platelet function for at least 14 days prior to blood collection. The study was performed under the guidelines of the Helsinki Declaration for human research and approved by the committee on the Ethics of Research in Human Experimentation at the Medical University of Lodz.

The blood was centrifuged for $12 \mathrm{~min}$ at $190 \times \mathrm{g}$ to obtain platelet-rich plasma (PRP). Then $1 \mathrm{ml}$ of PRP was layered onto the top of BSA-Sepharose 2B gel column and platelets were eluted from the column with Tyrode's buffer (134 mM NaCl, $12 \mathrm{mM} \mathrm{NaHCO}$, $2.9 \mathrm{mM} \mathrm{KCl}, 0.34 \mathrm{mM} \mathrm{Na} \mathrm{HPO}_{4}, 1 \mathrm{mM} \mathrm{MgCl}$, $10 \mathrm{mM}$ HEPES, $5 \mathrm{mM}$ glucose, $0.3 \%$ BSA, pH 7.4). The final platelet count in the suspensions of isolated cells estimated by photometric method was about $2 \times$ $10^{8} / \mathrm{ml}$.

\section{Measurement of platelets activation markers}

Flow cytometric measurements of activated GPIIb/IIIa (PAC-1) and P-selectin (CD62P) expression were performed in suspensions of isolated platelets, which were incubated $\left(10 \mathrm{~min}\right.$ at $\left.37^{\circ} \mathrm{C}\right)$ with HUVEC $\left(8 \times 10^{4}\right.$ cells/ well in 12 -well plate) pretreated with 2.5 or $15 \mu \mathrm{g} \mathrm{GAE} /$ $\mathrm{ml}$ the blackcurrant leaf extract for $24 \mathrm{~h}$. Optionally, $10 \mu \mathrm{M}$ ADP was added to the platelet suspensions in the wells with the HUVEC. After incubation, platelets were aspirated from the wells, mixed and labelled with anti-CD62 or PAC-1 antibodies and immediately fixed with CellFix ( $2 \mathrm{~h}$ at RT or overnight at $4{ }^{\circ} \mathrm{C}$ ). Following this, the expression of platelet surface $\mathrm{CD} 62 \mathrm{P}$ and the activated form of GPIIb/IIIa (monitored as PAC-1 binding) was analysed for 5000 platelets using a BD FACSCanto System (Becton Dickinson, San Diego, CA, USA).

\section{Statistical analysis}

Mean \pm SE or median and interquartile ranges are given for all parameters. The Shapiro-Wilk test was used to verify whether the data was normally distributed. Levene's test was used to verify the homogeneity of variances. The significance of differences between samples and controls (untreated cells) was determined with ANOVA for repeated measures, followed by multiple comparisons paired tests (either the paired Student $t$ test or Wilcoxon signed-rank test with Bonferroni's correction for multiple comparisons). For unpaired comparisons (analysis of the extract antioxidant activity determined by different methods; analysis of time dependentdifferences between $\mathrm{EC}_{50}$ and $\mathrm{EC}_{80}$ values, analysis of the extract effects on S1177 or T495 phosphorylation, analysis of the extract influence on apyrase activity), either the parametric one-way ANOVA or KruskalWallis non-parametric test was used, depending on data distribution and variance homogeneity, followed by Student $t$ test for independent samples or MannWhitney $U$ test. For the analysis of the related (indirect) values from the cell viability (presented as a percent of control - untreated cells) a single sample $t$ test was used. The $\mathrm{EC}_{50}$ and $\mathrm{EC}_{80}$ values were determined by nonlinear regression analysis, and the comparisons of curve parameters ( $\mathrm{EC}_{50}$ and Hill's slope) were based on Student $t$ test statistics (GraphPad Prism v. 5; GraphPad Software, San Diego, CA, USA).

\section{Results}

Phenolic composition and antioxidant activity of blackcurrant leaf extract

The phenolic composition, expressed as milligrammes per gramme of blackcurrant leaf extract, is summarised in Table 1. The results showed that flavanols were the most common phenolic compounds, representing $68 \%$ of the total polyphenols present in extract and that proanthocyanidins accounted for almost $90 \%$ of total flavanol content. In addition to monomers, flavanols are presented as oligomers and as polymers called condensed tannins or proanthocyanidins. The content of hydroxycinnamic acids and flavonols was above six times lower than that of total flavanols. The main component of flavonol was quercetin (quantified after acid hydrolysis), which made up almost $60 \%$ of flavonol and amounted to near $69 \%$ of the sum of estimated aglycones.

The extract from blackcurrant leaves was seen to possess a strong antioxidant capacity. However, the 
Table 1 Polyphenolic composition of blackcurrant leaf extract

\begin{tabular}{ll}
\hline & Content $[\mathrm{mg} / \mathrm{g}$ weight of extract $]$ \\
\hline Total polyphenols $^{\mathrm{a}}$ & $249.2 \pm 2.5$ \\
Total flavanols $^{\mathrm{b}}$ & $169.4 \pm 3.2$ \\
Total proanthocyanidins $^{\mathrm{c}}$ & $152.2 \pm 2.5$ \\
Hydroxycinnamic acids $^{\mathrm{d}}$ & $27.0 \pm 0.3$ \\
Flavonol derivatives $^{\mathrm{e}}$ & $23.8 \pm 0.1$ \\
Flavonol aglycons $^{\mathrm{f}}$ & \\
Quercetin $_{\text {Kaempferol }}$ & $13.6 \pm 0.2$ \\
Myricetin $_{\text {Gallotannins }}^{\mathrm{g}}$ & $5.4 \pm 0.1$ \\
\hline
\end{tabular}

Data shown as a mean \pm SE, $n=10$

${ }^{a}$ Determined by Folin-Ciocalteu reagent as gallic acid equivalents

${ }^{\mathrm{b}}$ Determined by vanillin reagent as $(+)$ catechin equivalents

${ }^{\mathrm{c}}$ Determined after acid depolymerization as cyanidin equivalents

${ }^{\mathrm{d}}$ Determined by HPLC method at $320 \mathrm{~nm}$ as chlorogenic acid equivalents

${ }^{\mathrm{e}}$ Determined by HPLC at $360 \mathrm{~nm}$ as quercetin equivalents

${ }^{\mathrm{f}}$ Determined by HPLC at $360 \mathrm{~nm}$ after acid hydrolysis as reference compounds

${ }^{\mathrm{g}}$ Determined by HPLC at $280 \mathrm{~nm}$ after acid hydrolysis as methyl gallate equivalents

antioxidant activity measured by ABTS was significantly higher than that determined by the FRAP method ( $2835 \pm 48$ vs. $2198 \pm 5 \mu \mathrm{M}$ Trolox/g of extract, respectively, $p<0.01, n=5)$. The antioxidant activity of blackcurrant extract measured by DPPH assay (2597 \pm $81 \mu \mathrm{M}$ Trolox/g, $n=6$ ) was not different from those obtained from ABTS and FRAP methods.

The influence of $R$. nigrum leaf extract on HUVEC viability

The influence of blackcurrant leaf extract on viability of endothelial cells was evaluated after 1-, 24- or 48-h incubation of HUVEC with plant extract. It was found that 24- and 48-h incubation with low concentrations of extract significantly increased cell viability, with a maximum at $2.5 \mu \mathrm{g}$ GAE/ml (Fig. 1a). This effect was especially evident for 48-h incubation where the significant enhancement in cell viability was at $0.1 \mu \mathrm{g} \mathrm{GAE} /$ $\mathrm{ml}, p<0.001$ (Fig. 1a). At higher concentrations (above $30 \mu \mathrm{g} \mathrm{GAE} / \mathrm{ml}$ for 24 and $48 \mathrm{~h}$ ), blackcurrant leaf extract significantly decreased HUVEC viability compared to untreated cells (Fig. 1b). The dose-dependent inhibition of viability was also analysed by calculating the concentrations of extract that elicited a response of $80 \%\left(\mathrm{EC}_{80}\right)$ or $50 \%\left(\mathrm{EC}_{50}\right)$ of maximal HUVEC viability for the cells incubated for 24 or $48 \mathrm{~h}$. The $\mathrm{EC}_{80}$ was $15.6 \pm 0.4 \mu \mathrm{g} \mathrm{GAE} / \mathrm{ml}$ for $24 \mathrm{~h}$ and was significantly higher than $\mathrm{EC}_{80}$ for $48 \mathrm{~h}(9.2 \pm$ $1.8 \mu \mathrm{g} \mathrm{GAE} / \mathrm{ml}), p<0.01$. The 24 and $48 \mathrm{~h} \mathrm{EC}_{50}$ values were comparable $(43.8 \pm 1.8$ and $39.9 \pm 5.0 \mu \mathrm{g} \mathrm{GAE} / \mathrm{ml}$, respectively). As blackcurrant extract was observed to have a weak effect on HUVEC viability after 1-h exposure, these results were excluded from further analyses.

To further analyse HUVEC function, we selected the extract concentration based on the viability results. The lowest used concentration was $2.5 \mu \mathrm{g} \mathrm{GAE} / \mathrm{ml}$. HUVEC incubated with the extract at $2.5 \mu \mathrm{g}$ GAE $/ \mathrm{ml}$ demonstrated the maximal cell viability: HUVEC (viability became increased by $25 \%$ for 24 -h incubation and by $32 \%$ for 48 -h incubation). Furthermore, we chose $15 \mu \mathrm{g} / \mathrm{ml}$ (EC80) as the maximal concentration of the extract, at which the extract did not significantly decrease HUVEC viability compared to the extractuntreated cells, although the maximal HUVEC viability (observed at $2.5 \mu \mathrm{g} \mathrm{GAE} / \mathrm{ml}$ ) became reduced by $20 \%$. We assumed that the extract concentration of $15 \mu \mathrm{g}$ GAE/ml (relevant to the EC80 value) might influence HUVEC function without the significant modification of cell viability.

CD39 expression on HUVEC incubated with the extract from blackcurrant leaves and determination of apyrase activity

After 24-h incubation of HUVEC with blackcurrant leaf extract, the CD39 expression significantly increased in a dose-dependent manner (up to $10 \%$ for $2.5 \mu \mathrm{g} \mathrm{GAE} / \mathrm{ml}$, up to $25 \%$ for $10 \mu \mathrm{g}$ GAE/ml and up to $33 \%$ for $15 \mu \mathrm{g} \mathrm{GAE} / \mathrm{ml}$, Fig. 2). The NTPDase (apyrase) activity was determined in the in vitro experimental model without cells, where the amount of Pi released from ATP by apyrase enzymatic reaction was measured. We observed that after the incubation of apyrase with the extract at the highest concentrations (10 and $15 \mu \mathrm{g} \mathrm{GAE} / \mathrm{ml}$ ) the enzyme activity was significantly reduced (Table 2). Simultaneously, the lower concentrations (0.25$2.5 \mu \mathrm{g} \mathrm{GAE} / \mathrm{ml}$ ) of extract did not change apyrase activity in the significant way. Also, the absorbance spectrum of blackcurrant leaf extract did not interfere with the absorbance of the product of malachite green assay measured at $655 \mathrm{~nm}$. 
Fig. 1 The effect of blackcurrant leaf extract on HUVEC viability. Data shown as a percent of control (untreated cells). Error bars refer to the standard errors obtained for eight experiments (each in four repeats). a The extract in low concentration significantly increased cell viability after $24 \mathrm{~h}$ (white boxes) and $48 \mathrm{~h}$ (grey boxes), ${ }^{*} p<0.001$ or less. b The extract significantly reduced cell viability for both incubation times, ${ }^{*} p<0.001$ (significance of differences was estimated by the single sample test with Bonferroni's correction in comparison to control: untreated cells)

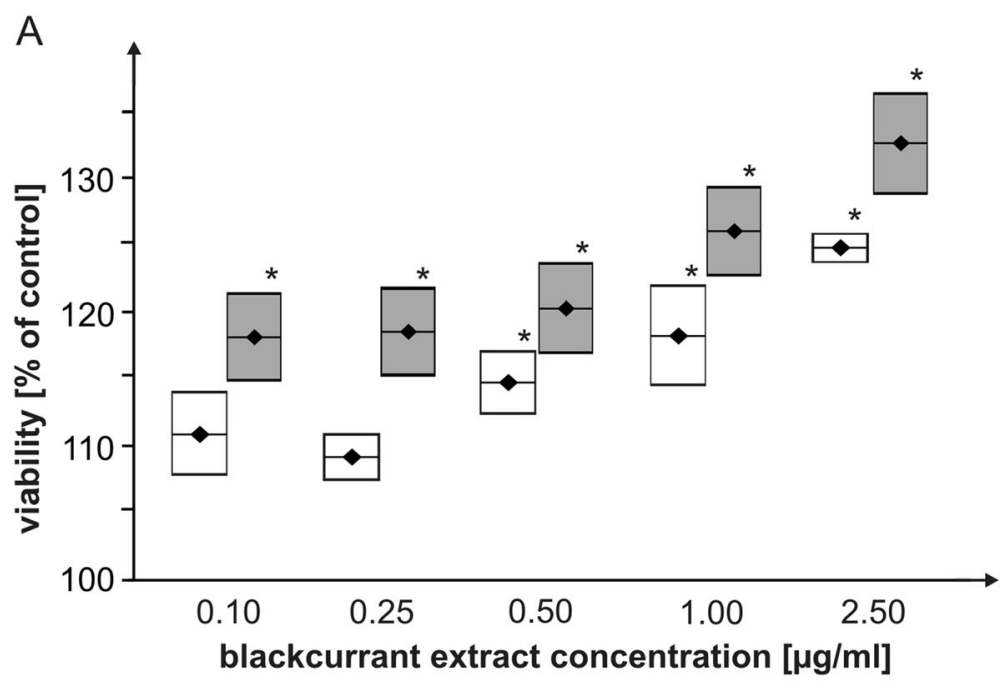

B

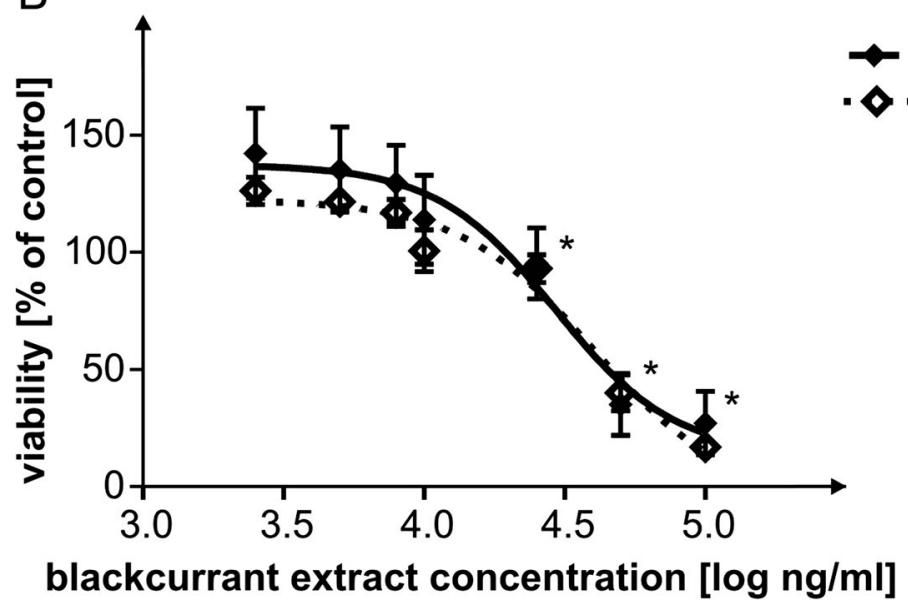

The effect of blackcurrant leaf extract on S1177 and T495 phosphorylation in eNOS protein

In endothelial cells incubated for $24 \mathrm{~h}$ with 2.5 and $15 \mu \mathrm{g} \mathrm{GAE} / \mathrm{ml}$ blackcurrant leaf extract, the activity of eNOS was analysed by monitoring protein phosphorylation at serine 1177 (S1177) and threonine 495 (T495) using flow cytometry. Blackcurrant leaf extract induced significant eNOS phosphorylation at S1177 $(p<0.05$ or less) and significantly decreased eNOS phosphorylation at T495 $(p<0.01)$ (Fig. 3). The effects of dephosphorylation were significantly higher $(p<0.05)$ for both concentrations (the decrease in T495 phosphorylation was $31 \pm 6 \%$ for $2.5 \mu \mathrm{g} \mathrm{GAE} / \mathrm{ml}$ and $48 \pm 6 \%$ for $15 \mu \mathrm{g}$ GAE $/ \mathrm{ml}$ vs. the increase in S1177 phosphorylation, $13 \pm 3 \%$ for $2.5 \mu \mathrm{g} \mathrm{GAE} / \mathrm{ml}$ and $18 \pm 7 \%$ for $15 \mu \mathrm{g} \mathrm{GAE} / \mathrm{ml}$, compared to untreated cells).

The effect of blackcurrant leaf extract on eNOS gene expression

The basal relative mRNA level for eNOS was $8.7 \pm 1.4$ in untreated cells and was unchanged after incubation with the tested extract (Fig. 4). Nevertheless, the incubation with the polyphenolic extract led to the increased relative mRNA level, mostly at the lower concentration (0.25 $\mu \mathrm{g} \mathrm{GAE} / \mathrm{ml})$; this difference, however, remained beyond statistical significance. 


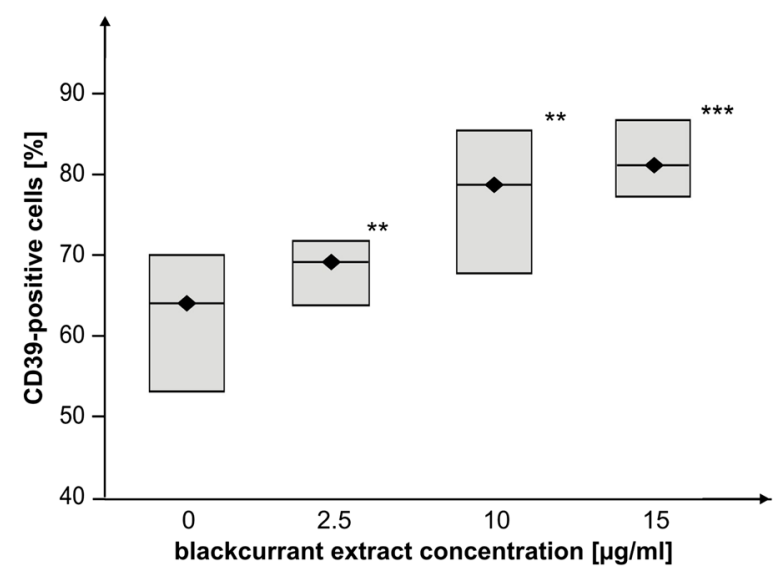

Fig. 2 The influence of blackcurrant leaf extract on CD39 expression on HUVEC. Data shown as median and interquartile range (Q1; Q3). Extract significantly increased CD39 expression dependently on concentration, $* * p<0.01$ or $* * * p<0.001$ (significance of differences was estimated by the paired $t$ test (for $15 \mu \mathrm{g} / \mathrm{ml}$ ) or Wilcoxon signed-rank test (for 2.5 and $10 \mu \mathrm{g} / \mathrm{ml}$ ) with Bonferroni's correction in comparison to control untreated cells

The effect of blackcurrant leaf extract on platelet-endothelium interactions

This study encompasses a simple model of monitoring blood platelet reactivity by analysing the expressions of selectin $\mathrm{P}$ (CD62P antigen) and the active form of GPIIb/IIIa (PAC-1) in blood platelets incubated with HUVEC pretreated with 2.5 and $15 \mu \mathrm{g}$ GAE/ml blackcurrant extract. A significant reduction of ADPinduced platelet reactivity was seen after incubation

Table 2 Apyrase activity after the incubation with blackcurrant leaf extract

\begin{tabular}{ll}
\hline $\begin{array}{l}\text { Blackcurrant leaf extract } \\
\text { concentration }[\mu \mathrm{g} \mathrm{GAE} / \mathrm{ml}]\end{array}$ & $\begin{array}{l}\text { Apyrase activity } \\
{[\mathrm{nmol} \mathrm{Pi} / \mathrm{ml} / \mathrm{min}]}\end{array}$ \\
\hline 0.00 & $38.5(37.5,59.8)$ \\
0.25 & $44.3(34.0,49.6)$ \\
0.50 & $45.1(36.5,57.2)$ \\
1.00 & $38.9(37.8,59.4)$ \\
2.50 & $38.1(36.3,52.6)$ \\
10.00 & $13.2(10.3,14.0) *$ \\
15.00 & $9.7(8.1,11.5) *$ \\
\hline
\end{tabular}

Data shown as median and interquartile range (Q1; Q3). The extract significantly reduced apyrase activity at the concentrations of 10 or $15 \mu \mathrm{g} \mathrm{GAE} / \mathrm{ml}$ compared to the probe without the extract, $* p<0.001$ (significance of differences was estimated by KruskalWallis non-parametric test followed by Mann-Whitney $U$ test)

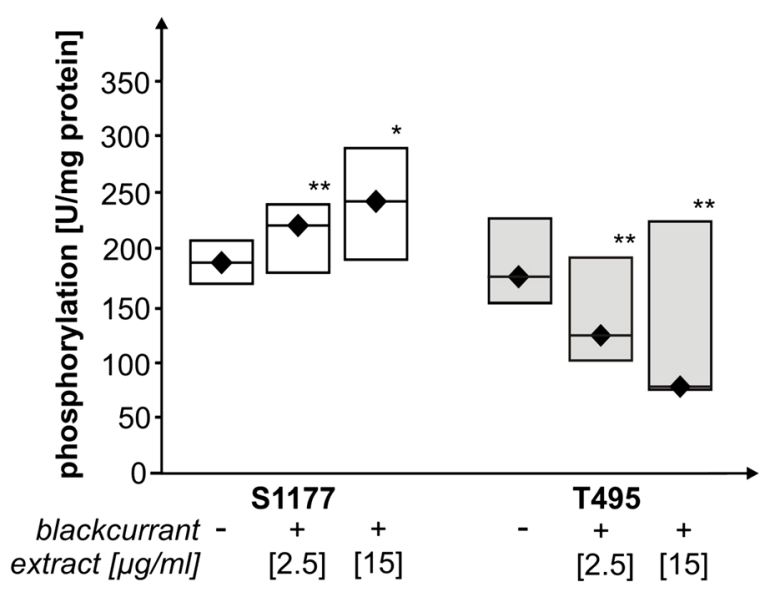

Fig. 3 The effect of blackcurrant leaf extract on 1177 serine (S1177) and 495 threonine (T495) phosphorylation in eNOS protein from HUVEC. Data is shown as median and interquartile range (Q1; Q3). Extract significantly increased serine (S1177) phosphorylation and decreased threonine phosphorylation (Thr495) in a concentration-dependent manner, ${ }^{*} p<0.05$ or $* * p<0.01$ (significance of differences was estimated by the paired $t$ test or Wilcoxon signed-rank test with Bonferroni's correction in comparison to control untreated cells)

with HUVEC. The effect was especially more pronounced for the fraction of PAC-1-positive platelets (43.7 $\pm 2.9 \%$ for platelets unicubated with HUVEC vs. $26.0 \pm 2.1 \%$ for platelets incubated with extractuntreated HUVEC, $p<0.001)$. Nevertheless, platelet

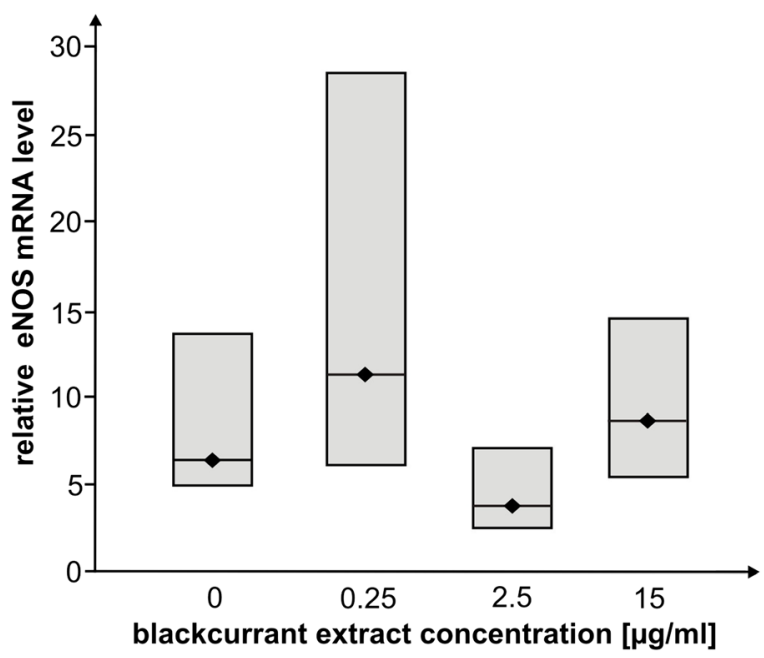

Fig. 4 The eNOS gene expression in HUVEC after the incubation with blackcurrant leaf extract. The eNOS mRNA level was determined by the standardisation to the reference gene (GAPDH) using ${ }^{\Delta}{ }^{\Delta}$ T method. Data shown as median and interquartile range (Q1; Q3), $n=13$. The extract did not significantly influence on eNOS gene expression 
reactivity did not change after exposure to extract-treated HUVEC compared to controls: platelets incubated with untreated HUVEC.

\section{Discussion}

Plant materials may contain varying quantities of different subclasses of phenolics, ranging from simple phenolic acids to polymerised tannins. Therefore, it is very difficult to develop the procedure suitable for the extraction of a whole spectrum of plant phenolics. For the extraction of phenolics from blackcurrant leaves, the acetone mixture was found to be more effective than other solvents and it enables the extraction of several classes of phenolic compounds with a good yield for flavonols, flavan-3-ols and anthocyanins [28, 29]. The results from the present study confirmed these observations: blackcurrant leaf acetone extract, additionally washed with chloroform to remove fat-soluble substances (especially chlorophylls), is rich in phenolic compounds (Table 1). The blackcurrant leaf extract is known to contain $25 \%$ phenolic compounds, most of which are flavanols, $90 \%$ of them being proanthocyanidins. The content of hydroxycinnamic acids and flavonols was less than one sixth that of total flavanols. Quercetin content, as quantified after acid hydrolysis, was 2.5 times higher than kaempferol and almost 17 times higher than myricetin content. Oszmiański et al. [20] and Liu et al. [15] described a detailed composition of blackcurrant leaf ethanol extract and indicated that the most important groups of phenolic compounds are flavonols (flavonol glycosides such as quercetin or kaempferol), proanthocyanidins and phenolic acids (hydroxycinnaminic acid conjugates). Also, Vagiri et al. reported the phenolic composition and indicated an optimised method for analysis of phenolic compounds in buds, leaves and fruits of blackcurrant which are known as very good sources of active phenolic compounds [31]. Many of the compounds detected in the leaves have been reported to have antiviral, antimicrobial and antidiabetic activities. Proantocyanidins, the main phenolic compounds in blackcurrant leaf extract, and naturally occurring in various plants, have been known for its anti-inflammatory and antiarthritic activities. They are reported to prevent heart diseases, and grape seed proanthocyanidins should be a potent cardioprotective compound.
Berries are known as a rich source of phenolics [7], but the recent studies underline a significant role of the polyphenols extracted from raw materials other than berry tissue, such as leaves [20]. It was reported that the leaves from apple, thornless black raspberry, red raspberry and strawberry had high antioxidant capacities and total phenolic content compared to their fruit tissues [32]. Tabart et al. demonstrated that blackcurrant leaves had a higher phenolic and antioxidant content than fully ripened berries, where the total phenolic level was correlated with antioxidant activity [28]. In addition, blackcurrant leaf extract possessed the strongest antioxidant activity compared to berries or buds as demonstrated by in vitro classical assays, but also in cellular models, such as endothelial cells and polymorphonuclear neutrophils. This study emphasises that the intracellular and extracellular scavenging properties of blackcurrant extract have no toxic effects [27]. Our study confirms that blackcurrant leaf extract is a good source of antioxidants with scavenging potential against free synthetic radicals $\mathrm{ABTS}^{\bullet+}$ and $\mathrm{DPPH}^{\bullet}$, and with high reducing power towards $\mathrm{Fe}^{3+}$ ions. Although these results may indicate a potential mechanism of the in vivo action of blackcurrant leaf extract, only clinical studies could finally confirm this assumption. Polyphenols, as the constituents of food, are poorly absorbed and extensively metabolised. In addition, they can bind to plasma proteins and form relatively stable complexes that are less active.

The aim of the present study was to investigate the antithrombotic function of human umbilical vein endothelial cells (HUVEC) in the presence of blackcurrant leaf extract. We targeted this objective by the monitoring of selected parameters of endothelial cell function that might be related to the modulation of blood platelet reactivity. We further hypothesised that the blackcurrant leaf extract might improve the antiplatelet action of endothelium by the increasing of CD39 expression and nitric oxide production, monitored as endothelial nitric oxide synthase (eNOS) activation and eNOS gene expression.

Typically, endothelial cells release NO in response to fluid shear stress and autacoids that mobilise intracellular calcium, such as thrombin or ADP. The eNOS enzyme is regulated post-translationally, but can also be influenced on the transcriptional level. Plant extracts rich in polyphenolic compounds were shown to be able to up-regulate eNOS and increase the activity of eNOS in cultured endothelial cells [5]. The consumption of 
flavanol-rich cocoa and purified anthocyanin supplementation improved endothelial function and vascular reactivity in hypercholesterolemic patients [33]. Moreover, in healthy subjects, an improved endothelial function was observed after administration of (-)-epicatehin (a major flavanol of cocoa), or after red wine or purple grape juice [24]. Our findings show that the extract from blackcurrant leaves significantly increased eNOS activity by modulating the phosphorylation rate of this protein; increased S1177 phosporylation (an activator site), and decreased T495 phosporylation (an inhibitor site) were observed in the extract-treated cells (Fig. 3). These findings are corroborated by other studies performed with other phenolic compounds. The phenolic-rich fraction of black tea was found to sharply enhance NO formation subsequent to the phosphorylation of eNOS at S1177 and the dephosphorylation of eNOS at T495 in porcine aortic endothelial cells. This stimulatory effect was calcium dependent, involving both intracellular and extracellular calcium and involved the p38 MAPK upstream of PI3-kinase/Akt pathway [1]. The endothelium-dependent relaxation was observed in response to exposure to some berry extracts, including blackcurrant extract, and the biological activity was predominantly associated with the fraction enriched in ellagitannins or anthocyanins [24]. Edirisinghe et al. report that anthocyanins from blackcurrant juice $(1 \mu \mathrm{l} /$ $\mathrm{ml}$ ) significantly increased the phosphorylation of Akt at S473 and eNOS at S1177 in human endothelial cells under in vitro conditions [5]. Also, it has been shown that red wine polyphenols induce the redox-sensitive activation of the PI3-kinase/Akt pathway in endothelial cells which, in turn, causes phosphorylation of eNOS, resulting in an increased formation of NO [19]. The mechanism underlying the activation of endothelial NO synthase (eNOS) remains unclear, but it has been suggested that polyphenols induce intracellular formation of reactive oxygen species such as superoxide anions and trigger the activation of eNOS by the PI3kinase/Akt pathway or they may act in a calciumdependent manner [24].

It was reported that blackcurrant leaf extract possesses anti-inflammatory properties $[6,27]$. The present study demonstrates for the first time that blackcurrant leaf extract may modulate endothelial cell function such as an increase in CD39 (ecto-ADPase) expression and eNOS activation. The ecto-ADPase expression in endothelial cells is one of the endogenous mechanisms which regulate blood platelet reactivity. The preserved function of CD39/ATPase is critical in the inhibition of platelet and neutrophil activation by keeping adenosine nucleotide levels at a low level [18]. Kaneider et al. report that thrombin downregulates CD39/ATPase activity but quercetin and resveratrol restores the decreased CD39/ATPase activity in human umbilical vein endothelial cells in response to thrombin, as demonstrated by the increased adenosine monophosphate (AMP) and adenosine levels seen in endothelial culture supernatants. Both polyphenols were found to inhibit thrombin-induced MAPK, JNK and focal adhesion kinase activities in endothelial cells: clear evidence that the levels of CD39 expression correlate with ATPase activity in human endothelial cells, platelets and selected monocytes, NK cells and megakaryocyte cell lines [10]. ATPase expressed by the investigated cells might influence signal transduction initiated by purinergic receptors by hydrolysis of their agonists. Koziak assumes that activity and expression of CD39/ATPase in the vasculature and other cells may have profound consequences for modulation of signals triggered by purinergic receptors, including apoptosis, antiinflammatory and prothrombotic responses [13].

The increased CD39 expression and the increased eNOS activation in HUVEC can be regarded as the beneficial markers of the improvement of antiplatelet action of endothelial cells. Unexpectedly, these assumptions were not confirmed in the experimental model of platelet-endothelial cell interactions. We did not observe the significant changes in platelet reactivity after their incubation with the extract-treated HUVEC. The explanation of this observation may relate to the analysis of apyrase activity after the incubation with blackcurrant leaf extract. The increased CD39 expression appears not a sufficient indicator of antiplatelet action of HUVEC, because blackcurrant extract at the higher concentrations (10 or $15 \mu \mathrm{g}$ GAE/ml) significantly reduced apyrase activity or did not affect apyrase activity at lower concentrations (up to $2.5 \mu \mathrm{g} \mathrm{GAE} / \mathrm{ml}$ ). It is possible that some compounds of extract may interact with apyrase followed by the enzyme inhibition. Also, the increased eNOS activation without the accompanying increase of the eNOS mRNA in HUVEC treated with the extract was not associated with the reduced blood platelet reactivity.

In this study, the biological antithrombotic effects of blackcurrant leaf extract were investigated at a few concentrations selected in the cell viability assay. We noticed that blackcurrant leaf extract may modulate the viability 
of endothelial cells in a time- and concentrationdependent manner. Regardless of exposure time, at lower concentrations, blackcurrant leaf extract was found to improve HUVEC viability, whereas at higher concentrations (above $30 \mu \mathrm{g} \mathrm{GAE} / \mathrm{ml}$ ), it significantly decreased HUVEC viability as compared to the untreated cells. However, EC80 values estimated for 24 and 48-h incubation of HUVEC with blackcurrant extract were significantly different, which means that longer incubation of HUVEC with blackcurrant leaf extract intensifies its anti-proliferative effect. Such an increased cell viability effect of blackcurrant leaf extract for lower concentrations, which are nutritionally relevant doses for phenolic compounds, may play a crucial role in physiological angiogenic processes, such as wound repair or tissue regeneration. Additionally, we observed that in the range of concentrations known to improve cell viability, the extract also increased eNOS activation or enhanced CD39 expression. Per analogiam, some authors have suggested a significant role of phenolic compounds isolated from Panax ginseng in angiogenesis. The extract significantly enhanced HUVEC viability and this effect was accompanied by phosphorylation of eNOS, as well as the increased NO production [12]. In the presence of SKE-treated cells (the extract from Stewartia koreana leaves, $50 \mu \mathrm{g} / \mathrm{ml}$, incubation by $24 \mathrm{~h}$ ) cell proliferation increased twofold, and almost no cytotoxic effects or induced morphological changes were noted in the treated cells, thus indicating that the enhanced proliferation of endothelial cells occurred at non-cytotoxic concentrations. Based on these outcomes, Stewartia koreana extracts have been proposed as potential agents useful in accelerating vascular wound healing or promoting the growth of collateral blood vessels in ischaemic tissues [14].

We are aware that the most relevant limitation of our study is the choice of blackcurrant leaf extract concentrations to monitor the endothelial cell functions. We have known that the selected concentrations $(2.5 ; 10$ or $15 \mu \mathrm{g} / \mathrm{ml}$ ) were higher compared to those used in the polyphenol in vivo studies (where the maximal plasma concentration of polyphenols and its metabolites usually did not exceed $10 \mu \mathrm{M}(1.8 \mu \mathrm{g} / \mathrm{ml})$ and depended upon the kind of phenolic compound) [17]. Epidemiological studies have shown that the significant biological effects of polyphenols can be observed after a few days or a few weeks of the diets rich in polyphenolic compounds. In our experimental model of human endothelial cells in tissue cultures, we monitored the cell function after the short 24-h incubation instead of a few days' incubation and we used the higher concentrations to demonstrate the extract effects. Simultaneously, we have been conscious that the increasing of extract concentrations could result in experimental artefacts. However, in many of the published in vitro studies, the health benefits have been demonstrated using the concentrations much higher $(1-100 \mu \mathrm{M})$ than those achievable in a body.

In conclusion, blackcurrant leaf extract, which is rich in proanthocyanidins, may modulate endothelial cell function in a concentration-dependent manner. The extract has been found to damage endothelial cells at concentrations above $30 \mu \mathrm{g} \mathrm{GAE} / \mathrm{ml}$. However, at the lower concentrations, its effects were beneficial. The extract increased endothelial cell viability and increased CD39 expression, but collaterally reduced apyrase activity; it also up-regulated eNOS activation by influencing enzyme phosphorylation rate, however, with no concomitant affecting eNOS gene expression. These observations lead to the conclusion that the blackcurrant leaf extract may improve endothelial cell viability at low physiological concentrations, however, without affecting antiplatelet action of endothelium. Importantly, the increasing of the extract concentrations apparently reverses these beneficial effects. Overall, we have to sum up with the stating that the in vitro findings on biological activity of extracts cannot be easily translated to in vivo physiological conditions.

Acknowledgments This work was supported by the grant "Production of polyphenol extracts of plant origin with antiplatelet and cardioprotective properties - FLAWOPIRYNA" UDAPOIG.01.03.01-10-129/08-00, cofinanced by the European Union from the European Regional Development Fund within the framework of the Innovative Economy Operational Programme.

\section{References}

1. Anter E, Thomas SR, Schulz E, Shapira OM, Vita JA, Keaney JF Jr (2004) Activation of endothelial nitric-oxide synthase by the p38 MAPK in response to black tea polyphenols. J Biol Chem 279:46637-46643

2. Benzie IF, Strain JJ (1996) The ferric reducing ability of plasma (FRAP) as a measure of "antioxidant power": the FRAP assay. Anal Biochem 239:70-76

3. Bordonaba JG, Terry LA (2008) Biochemical profiling and chemometric analysis of seventeen UK-grown black currant cultivars. J Agric Food Chem 56:7422-7430 
4. Dyrby M, Westergaard N, Stapelfedt H (2001) Light and heat sensitivity of red cabbage extract in soft drink model systems. Food Chem 72:431-437

5. Edirisinghe I, Banaszewski K, Cappozzo J, McCarthy D, Burton-Freeman BM (2011) Effect of black currant anthocyanins on the activation of endothelial nitric oxide synthase (eNOS) in vitro in human endothelial cells. J Agric Food Chem 59:8616-8624

6. Garbacki N, Tits M, Angenot L, Damas J (2004) Inhibitory effects of proanthocyanidins from Ribes nigrum leaves on carrageenin acute inflammatory reactions induced in rats. BMC Pharmacol 4:25

7. Gopalan A, Reuben SC, Ahmed S, Darvesh AS, Hohmann J, Bishayee A (2012) The health benefits of blackcurrants. Food Funct 3:795-809

8. Goubareva I, Gkaliagkousi E, Shah A, Queen L, Ritter J, Ferro A (2007) Age decreases nitric oxide synthesis and responsiveness in human platelets and increases formation of monocyteplatelet aggregates. Cardiovasc Res 75:793-802

9. Hansen MB, Nielsen SE, Berg K (1989) Re-examination and further development of a precise and rapid dye method for measuring cell growth/cell kill. J Immunol Methods 119:203-210

10. Kaneider NC, Mosheimer B, Reinisch N, Patsch JR, Wiedermann CJ (2004) Inhibition of thrombin-induced signaling by resveratrol and quercetin: effects on adenosine nucleotide metabolism in endothelial cells and plateletneutrophil interactions. Thromb Res 114:185-194

11. Kim DO, Lee KW, Lee HJ, Lee CY (2002) Vitamin C equivalent antioxidant capacity (VCEAC) of phenolic phytochemicals. J Agric Food Chem 50:3713-3717

12. Kim YM, Namkoong S, Yun YG, Hong HD, Lee YC, Ha KS, Lee H, Kwon HJ, Kwon YG, Kim YM (2007) Water extract of Korean red ginseng stimulates angiogenesis by activating the PI3K/Akt-dependent ERK1/2 and eNOS pathways in human umbilical vein endothelial cells. Biol Pharm Bull 30: 1674-1679

13. Koziak K, Sevigny J, Robson SC, Siegel JB, Kaczmarek E (1999) Analysis of CD39/ATP diphosphohydrolase (ATPDase) expression in endothelial cells, platelets and leukocytes. Thromb Haemost 82:1538-1544

14. Lee TH, Lee GW, Kim CW, Bang MH, Baek NI, Kim SH, Chung DK, Kim J (2010) Stewartia koreana extract stimulates proliferation and migration of human endothelial cells and induces neovasculization in vivo. Phytother Res 24:20-25

15. Liu P, Kallio H, Yang B (2014) Flavonol glycosides and other phenolic compounds in buds and leaves of different varieties of black currant (Ribes nigrum L.) and changes during growing season. Food Chem 160:180-189

16. Livak KJ, Schmittgen TD (2001) Analysis of relative gene expression data using real-time quantitative PCR and the 2(delta delta $\mathrm{C}(\mathrm{T})$ ) method. Methods 25:402-408

17. Manach C, Williamson G, Morand C, Scalbert A, Remesy C (2005) Bioavailability and bioefficacy of polyphenols in humans. I. Review of 97 bioavailability studies. Am J Clin Nutr 81:230S-242S

18. Marcus AJ, Broekman MJ, Drosopoulos JH, Olson KE, Islam N, Pinsky DJ, Levi R (2005) Role of CD39 (NTPDase-1) in thromboregulation, cerebroprotection, and cardioprotection. Semin Thromb Hemost 31:234-246
19. Ndiaye M, Chataigneau M, Lobysheva I, Chataigneau T, Schini-Kerth VB (2005) Red wine polyphenol-induced, endothelium-dependent NO-mediated relaxation is due to the redox-sensitive PI3-kinase/Akt-dependent phosphorylation of endothelial NO-synthase in the isolated porcine coronary artery. FASEB J 19:455-457

20. Oszmianski J, Wojdylo A, Gorzelany J, Kapusta I (2011) Identification and characterization of low molecular weight polyphenols in berry leaf extracts by HPLC-DAD and LCESI/MS. J Agric Food Chem 59:12830-12835

21. Ramli J, CalderonArtero P, Block RC, Mousa SA (2011) Novel therapeutic targets for preserving a healthy endothelium: strategies for reducing the risk of vascular and cardiovascular disease. Cardiol J 18:352-363

22. Re R, Pellegrini N, Proteggente A, Pannala A, Yang M, RiceEvans C (1999) Antioxidant activity applying an improved ABTS radical cation decolorization assay. Free Radic Biol Med 26:1231-1237

23. Rosch D, Bergmann M, Knorr D, Kroh LW (2003) Structureantioxidant efficiency relationships of phenolic compounds and their contribution to the antioxidant activity of sea buckthorn juice. J Agric Food Chem 51:4233-4239

24. Schini-Kerth VB, Auger C, Kim JH, Etienne-Selloum N, Chataigneau T (2010) Nutritional improvement of the endothelial control of vascular tone by polyphenols: role of $\mathrm{NO}$ and EDHF. Pflugers Arch 459:853-862

25. Stone DA, Hawke MW, LaMonte M, Kittner SJ, Acosta J, Corretti M, Sample C, Price TR, Plotnick GD (1995) Ulcerated atherosclerotic plaques in the thoracic aorta are associated with cryptogenic stroke: a multiplane transesophageal echocardiographic study. Am Heart J 130:105-108

26. Swain T, Hillis WE (1959) The phenolics constituents of Prunus domestica III. J Sci Food Agric 10:63-68

27. Tabart J, Franck T, Kevers C, Pincemail J, Serteyn D, Defraigne JO, Dommes J (2012) Antioxidant and antiinflammatory activities of Ribes nigrum extracts. Food Chem 131:1116-1122

28. Tabart J, Kevers C, Evers D, Dommes J (2011) Ascorbic acid, phenolic acid, flavonoid, and carotenoid profiles of selected extracts from Ribes nigrum. J Agric Food Chem 59: 4763-4770

29. Tabart J, Kevers C, Pincemail J, Defraigne JO, Dommes J (2006) Antioxidant capacity of black currant varies with organ, season, and cultivar. J Agric Food Chem 54:6271-6276

30. Tahvonen RL, Schwab US, Linderborg KM, Mykkanen HM, Kallio HP (2005) Black currant seed oil and fish oil supplements differ in their effects on fatty acid profiles of plasma lipids, and concentrations of serum total and lipoprotein lipids, plasma glucose and insulin. J Nutr Biochem 16:353-359

31. Vagiri M, Ekholm A, Andersson SC, Johansson E, Rumpunen K (2012) An optimized method for analysis of phenolic compounds in buds, leaves, and fruits of black currant (Ribes nigrum L.). J Agric Food Chem 60:10501-10510

32. Wang SY, Lin HS (2000) Antioxidant activity in fruits and leaves of blackberry, raspberry, and strawberry varies with cultivar and developmental stage. J Agric Food Chem 48: 140-146

33. Zhu Y, Xia M, Yang Y, Liu F, Li Z, Hao Y, Mi M, Jin T, Ling W (2011) Purified anthocyanin supplementation improves endothelial function via NO-cGMP activation in hypercholesterolemic individuals. Clin Chem 57:1524-1533 